\title{
Penerapan Fuzzy Mamdani Untuk Sistem Pendukung Keputusan Pemilihan Telepon Seluler
}

\author{
Wira Buana \\ Dosen STMIK Jayanusa \\ wira_buana59@yahoo.com
}

\begin{abstract}
ABSTRAK
Fuzzy logic merupakan salah satu pendekatan yang menggunakan beberapa tahapan tertentu. Beberapa modelfuzzy logic banyak diterapkan dalam menyelesaikan berbagai permasalahan salah satunya adalah fuzzy Mamdani.Banyaknya jenis telepon seluler yang tersedia dipasaran membuat para konsumen menjadi kesulitan untuk menentukan pilihannya. Permasalahan yang dipilih adalah membangun sistem pendukung pengambilan keputusan untuk membantu memberikan pilihan ponsel bagi para konsumen berdasarkan kriteria-kriteria yang diinginkan oleh konsumen tersebut. Kriteria yang digunakan dalam membantu menentukan pilihan ponsel yang diinginkan konsumen antara lain berdasarkan pada harga, ukuran layar ponsel, dan kapasitas memori. Dikarenakan kriteria-kriteria tersebut sifatnya relatif maka dibuat fuzzy Mamdani yang dapat digunakan model untuk mendapatkan pilihan yang tepat dari suatu yang samar. Hasil penelitian dalam pemilihan telepon seluler, berdasarkan data telepon seluler penulis melakukan beberapa pengujian yaitu pengujian dengan fuzzy dan pengujian menggunakan software Matlab yang dapat membantu mempercepat proses pengolahan data dan mendapatkan sebuah keputusan dengan cepat.
\end{abstract}

Kata Kunci :SistemPendukungKeputusan, Himpunan Fuzzy, TeleponSeluler

\section{PENDAHULUAN}

Perkembangan ilmu pengetahuan sangat pesat berbagai bentuk aktifitas kerja telah banyak diambil alih oleh teknologi informasi (TI), penerapan komputer untuk menunjang aktifitas perusahaan, instansi maupun perseorangan membuktikan adanya perkembangan teknik informasi yang demikian cepat, bahkan aplikasi sekarang ini digunakan para konsumen dalam pengambilan keputusan. Fuzzy logic merupakan salah satu pendekatan yang menggunakan beberapa tahapan tertentu. Beberapa model fuzzy logic banyak diterapkan dalam menyelesaikan berbagai permasalahan salah satunya adalah fuzzy Mamdani. (Rizky Pahlevi, at.al (2013).

Logika fuzzy juga dapat diterapkan untuk ekonomi, psikologi, pemasaran, peramalan cuaca, biologi, dan politik. Oleh karena itu, berdasarkan pada konsep sistem pendukung keputusan (DSS), kerangka terpadu yang menggabungkan teori kabur dalam pemilihan telepon seluler (Rawabdeh, 2012).

Banyaknya jenis telepon seluler yang tersedia dipasaran membuat para konsumen menjadi kesulitan untuk menentukan pilihannya. Permasalahan yang dipilih adalah membangun sistem pendukung pengambilan keputusan untuk membantu memberikan pilihan ponsel bagi para konsumen berdasarkan kriteria-kriteria yang diinginkan oleh konsumen tersebut.

\section{LANDASANTEORI \\ 2.1 Fuzzy Logic}

Logika fuzzy merupakan suatu cara untuk memetakan suatu ruang masukan ke dalam suatu ruang keluaran. Dalam teori logika fuzzy dikenal 
himpunan fuzzy (fuzzy set). Merupakan pengelompokan sesuatu berdasarkan variabel bahasa yang dinyatakan dalam fungsi keanggotaan (membership function). (Heru Dibyo Laksono dan Hansi Effendi, 2011).

\subsection{Operator LogikaFuzzy}

1. Operator $A N D$

Operator ini menghasilkan nilai keanggotaan terkecil antara elemen-elemen pada himpunan-himpunan terkait.

$$
\mu A \cap B=g \mu A X, \mu B X \quad x \in X
$$

2. Operator $O R$

Operator ini menghasilkan nilai keanggotaan terbesar antar elemen-elemen pada himpunan - himpunan terkait.

$$
\mu A \cup B=f \mu A x, \mu B \quad x \quad x \in X
$$

3. Operator NOT

Operator complement dinyatakan dengan negasi yang tegas.

$$
\mu \sim A=-\mu A x x \in X
$$

\subsection{Model Fuzzy}

1. Metode Tsukamoto

Setiap konsekuen pada aturan yang berbentuk IF-Then harus direpresentasikan dengan suatuh impunan fuzzy dengan fungsi keanggotaan yang monoton.

2. Metode Mamdani

Sering dikenal dengan nama Metode MaxMin.

3. Metode Sugeno

Penalaran dengan metode Sugeno hamper sama dengan penalaran mamdani, hanya saja output (konsekuen) system tidak berupa himpunan fuzzy.

4. Model Tahani

Analisis data dilakukanuntukmengolah data yang telahdidapatdanmengelompokan data sesuaidengankebutuhanperancangan.

\subsection{FungsiKeanggotaan}

Fungsi keanggotaan (membership function) adalah suatu kurva yang menunjukkan pemetaan titik-titik input data kedalam nilai keanggotaannya (sering disebut dengan derajat keanggotaan) yang memiliki interval 0 sampai 1. Salah satu cara yang dapat digunakan untuk mendapatkan niai keanggotaan adalah dengan melalui pendekatan fungsi.

Representasi Linear Naik

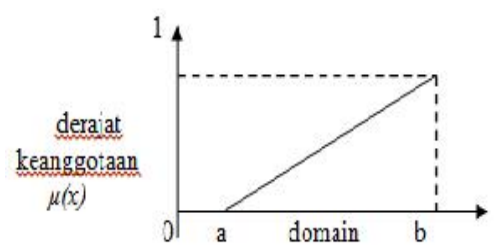

Gambar 2.1 Representasi Linear Naik

Fungsi keanggotaan:

$$
\mu[x]=\left\{\begin{array}{lr}
0 ; & x \leq a \\
(x-a) /(b-a) ; & a \leq x \leq b \\
1 ; & x \geq b
\end{array}\right.
$$

Representasi Linear Turun

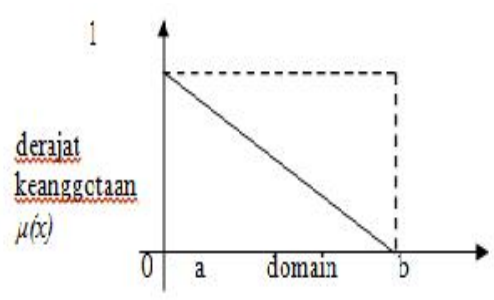

\section{Gambar 2.2 Representasi Linear Turun}

Fungsi keanggotaan:

$$
\mu[x]=\left\{\begin{array}{lr}
(b-x) /(b-a) ; & a \leq x \leq b \\
0 ; & x \geq b
\end{array}\right.
$$

Representasi Kurva Segitiga

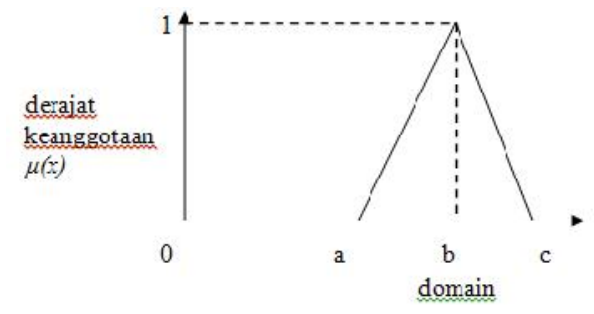

Gambar 2.3 Representasi Kurva Segitiga 


\section{Jurnal Edik Informatika \\ E-ISSN : 2541-3716}

Penelitian Bidang Komputer Sains dan Pendidikan Informatika

V2.i1(138-143)

Fungsi keanggotaan:

$$
\mu[x]=\left\{\begin{array}{lr}
0 ; & x \leq a \text { atau } x \geq c \\
(x-a) /(b-a) ; & a \leq x \leq b \\
(b-x) /(c-b) ; & b \leq x \leq c
\end{array}\right.
$$

Representasi Kurva Trapesium

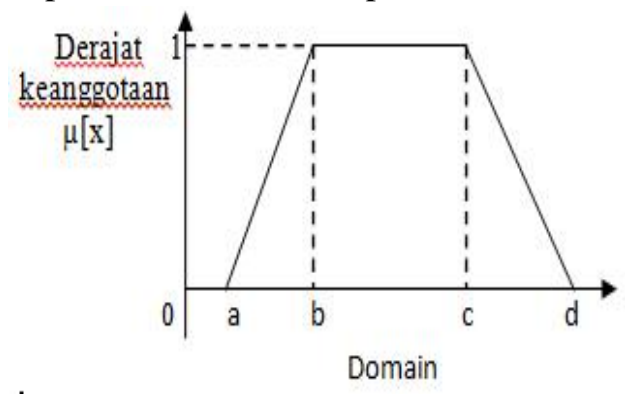

Gambar 2.4 Representasi Kurva Trapesium

$$
\mu[x]=\left\{\begin{array}{lr}
0 ; & x \leq a \text { atau } x \geq d \\
(x-a) /(b-a) ; & a \leq x \leq b \\
1 ; & b \leq x \leq c \\
(d-x) /(d-c) ; & x \geq d
\end{array}\right.
$$

\subsection{MetodeFuzzyMamdani}

Metode Mamdani sering juga dikenal dengan nama Metode Max-Min. Untuk mendapatkan output, diperlukan empat tahapan (Rizky Pahlevi, at.al (2013):

1.Pembentukan Himpunan Fuzzy yang akan membagi variabel input maupun output ke dalam satu atau lebih himpunan fuzzy (fuzzyfikasi).

2.Penerapan fungsi implikasi yang menggunakan fungsi min.

3.Komposisi aturan.

4.Proses defuzzyfikasi

\section{TAHAPPENELITIAN}

Pada penelitian ini penulis mentetapkan tiga variabel input (ukuran, harga memori dan kamera) dan satu variabel output yaitu keputusan.

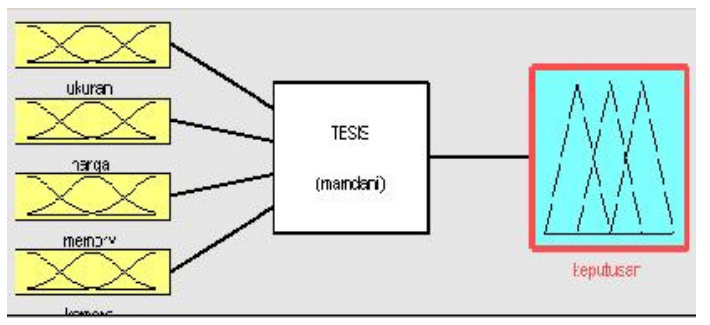

Gambar 1 Variabel Input dan Output

Ada 4 tahap yang harus dilalui untuk memperoleh output dengan metode mamdani:

1. Pembentukan himpunan fuzzy

a. Variabel ukuran layar Adapun gambar himpunan fuzzy Variabel ukuran layara dalah:

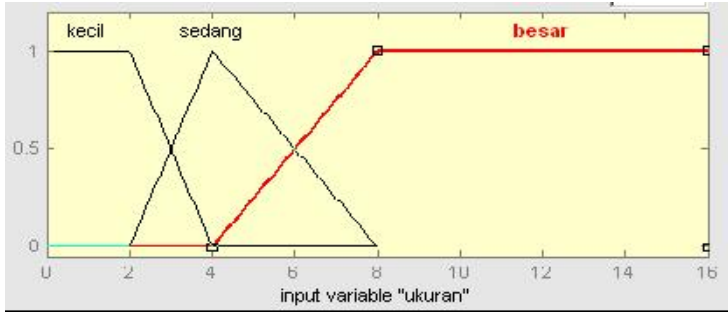

Gambar 2 Himpunan Fuzzy Ukuran

Untuk memperjelas grafik di atas ada pada keterangan tabel di bawah ini:

Tabel 1. Himpunan Fuzzy Ukuran

\begin{tabular}{|c|l|l|}
\hline $\begin{array}{c}\text { Semesta } \\
\text { Pembicaraan }\end{array}$ & \multicolumn{1}{|c|}{ Nama Himpunan } & Domain \\
\hline $0-16$ & - Kecil & {$[0-4]$} \\
& - Sedang & {$[2-8]$} \\
& - Besar & {$[4-16]$} \\
\hline
\end{tabular}

b. Variabel Harga

Adapun gambar himpunan fuzzy variabel berat badan adalah: 


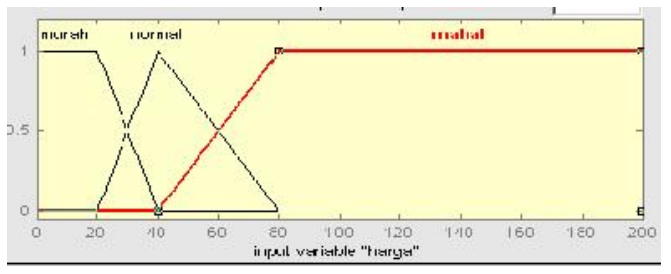

Gambar 3 HimpunanFuzzy Harga

Untuk memperjelas grafik di atas ada pada keterangan tabel di bawah ini:

\section{Tabel 2. Himpunan Fuzzy Harga}

\begin{tabular}{|c|c|c|}
\hline $\begin{array}{c}\text { Semesta } \\
\text { Pembicaraan }\end{array}$ & $\begin{array}{c}\text { Nama Himpunan } \\
\text { Fuzzy }\end{array}$ & Domain \\
\hline $0-100$ & $\begin{array}{l}\text { Murah } \\
\text { Normal } \\
\text { Mahal }\end{array}$ & $\begin{array}{l}0-40 \\
20-80 \\
40-200\end{array}$ \\
\hline
\end{tabular}

c. Variabel KapasitasMemori

Adapun gambar himpunan fuzzy variabel KapasitasMemori adalah:

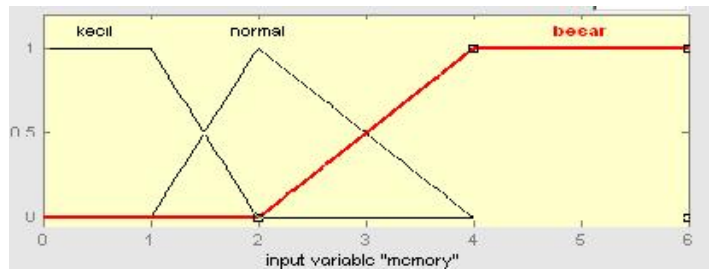

\section{Gambar 4 HimpunanFuzzy Kapasitas Memori}

Untuk memperjelas grafik di atas ada pada keterangan tabel di bawah ini:

Tabel 3. Himpunan Fuzzy Kapasitas Memori

\begin{tabular}{|l|l|l|}
\hline $\begin{array}{c}\text { Semesta } \\
\text { Pembicaraan }\end{array}$ & \multicolumn{1}{|c|}{ Nama Himpunan } & Domain \\
\hline $0-6$ & Kecil & \\
& Normal & {$[0-2]$} \\
& Besar & {$[1-4]$} \\
& {$[2-6]$} \\
\hline
\end{tabular}

\section{d.Variabel Kamera}

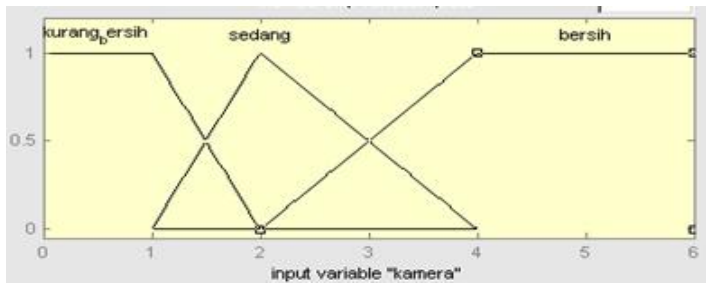

Gambar 5 HimpunanFuzzy Kamera

Untuk memperjelas grafik di atas ada pada keterangan tabel di bawah ini:

Tabel 4. Himpunan Fuzzy Kamera

\begin{tabular}{|l|l|l|}
\hline $\begin{array}{c}\text { Semesta } \\
\text { Pembicaraan }\end{array}$ & \multicolumn{1}{|c|}{ Nama Himpunan } & Domain \\
\hline $0-6$ & Kurang bersih & \\
& Sedang & {$[0-2]$} \\
& Bersih & {$[1-4]$} \\
& {$[2-6]$} \\
\hline
\end{tabular}

e. Variabel Output

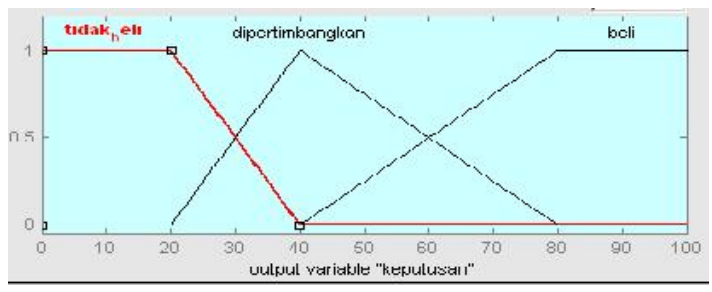

Gambar 6 HimpunanFuzzy pada variabel

\section{Output}

Untuk memperjelas grafik di atas ada pada keterangan tabel di bawah ini:

Tabel 5. Himpunan Fuzzy Variabel Output

\begin{tabular}{|c|l|c|}
\hline $\begin{array}{c}\text { Semesta } \\
\text { Pembicaraan }\end{array}$ & \multicolumn{1}{|c|}{$\begin{array}{c}\text { Nama Himpunan } \\
\text { Fuzzy }\end{array}$} & Domain \\
\hline \multirow{3}{*}{$0-100$} & Tidak Beli & $0-40$ \\
\cline { 2 - 3 } & Dipertimbangkan & $20-80$ \\
\cline { 2 - 3 } & Beli & $40-100$ \\
\hline
\end{tabular}


Contoh kasus:

Dari data spesifikasi telepon sellular diambil data merek Vitell V711 dimana sampel Ukuran 2.3 Inc, Harga \$40, Memori sebanyak 2 GB dan Kamera 1.3 MP.

1. Pembentukan himpunan fuzzy

a. Himpunan fuzzy untuk Ukuran Layar 2.3, terletak pada kurva kecil.

$\mu$ kecil $[2,3]=(4-2,3) /(4-2)$

$$
\begin{aligned}
& =1.7 / 2 \\
& =0,85
\end{aligned}
$$

$\mu$ sedang $[2,3]=(2,3-2) /(4-2)$

$$
=0,3 / 2
$$$$
=0,15
$$

b. Himpunan fuzzyu ntuk Harga \$40.Harga $\$ 40$ terletak pada kurva normal.

$\mu$ normal $[\$ 40]=(x-a) /(b-a)$

$$
\begin{aligned}
& =(40-20) /(40-20) \\
& =2 \\
& =1
\end{aligned}
$$

$\mu$ murah $[\$ 40]=(40-20) /(40-20)$

$$
\begin{aligned}
& =20 / 20 \\
& =1
\end{aligned}
$$

c. Himpunan fuzzy untuk Kapasitas Memori 2 GB nilai 2 GB terletak padakurva kecil.

$\mu$ keci $1[2$ GB $]=(\mathrm{d}-\mathrm{x}) /(\mathrm{d}-\mathrm{c})$

$$
\begin{aligned}
& =(2-1) /(2-1) \\
& =1 / 1 \\
& =1 \\
& =(2-1) /(2-1) \\
& =1 / 1 \\
& =1
\end{aligned}
$$

unormal $[2 \mathrm{~GB}]=(2-1) /(2-1)$

d. Himpunan fuzzy untuk Kapasitas Kamera 2 MP nilai 2 MP terletak pada kurva kurang bersih.

$$
\begin{aligned}
\mu \text { sedang }[1,3 \mathrm{MP}] & =(\mathrm{x}-\mathrm{a}) /(\mathrm{b}-\mathrm{a}) \\
= & (1,3-1) /(2-1) \\
= & 0,3 / 1 \\
= & 0,3
\end{aligned}
$$

2. Pengumpulan (Aggregation)

Berdasarkan hasil fuzzy fikasi di dapat bahwa rule yang terlibat berjumlah 2 rule yaitu :
[Rule 5] IF (Ukuran Layar is Kecil) AND (Harga is Normal) AND (Kapasitas Memori is Normal) AND (Kamera is sedang) THEN Keputusan dipertimbangkan.

apredikat $5=\mu$ ukuranlayar $\cap \mu$ harga $\cap \mu$ kapasitas memori $\cap \mu$ kamera

$=\min (\mu$ ukuran layar [2,3] $\cap \mu$ harga [40] $\cap \mu$ kapasitas memori [2] $\cap \mu$ kamera [1.3 MP]).

$$
=\min (0,85 ; 1 ; 1 ; 0,3)
$$$$
=0,3
$$

[Rule 14] IF (Ukuran Layar is Sedang) AND (Harga is Murah) AND (Kapasitas Memori is Normal) AND (Kamera is Sedang) THEN Keputusa Beli.

$\alpha$ predikat $14=\mu$ ukuran layar $\cap \mu$ harga $\cap \mu$ kapasitas memori $\mu \cap$ kamera $=\min (\mu$ ukuran layar [2,3] $\cap \mu$ haga [40] $\cap \mu$ kapasitas memori [2] $\cap \mu$ kamera [1,3] $=\min (0,15 ; 1 ; 1 ; 0,3)$

$$
=0,3
$$

3. Komposisi aturan

$\mu(\mathrm{z})=\max (0,3 ; 0,15 ; 1 ; 1 ; 1)$

$$
=1
$$

\section{Defuzzifikasi}

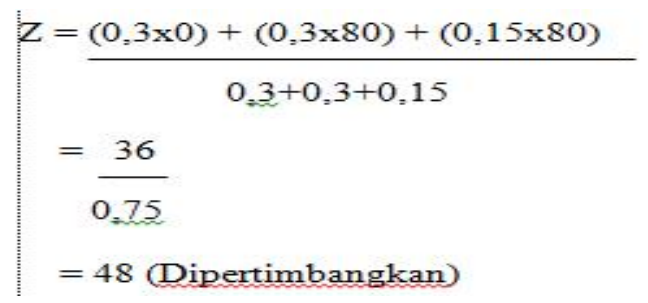




\section{HASILPENGUJIAN}

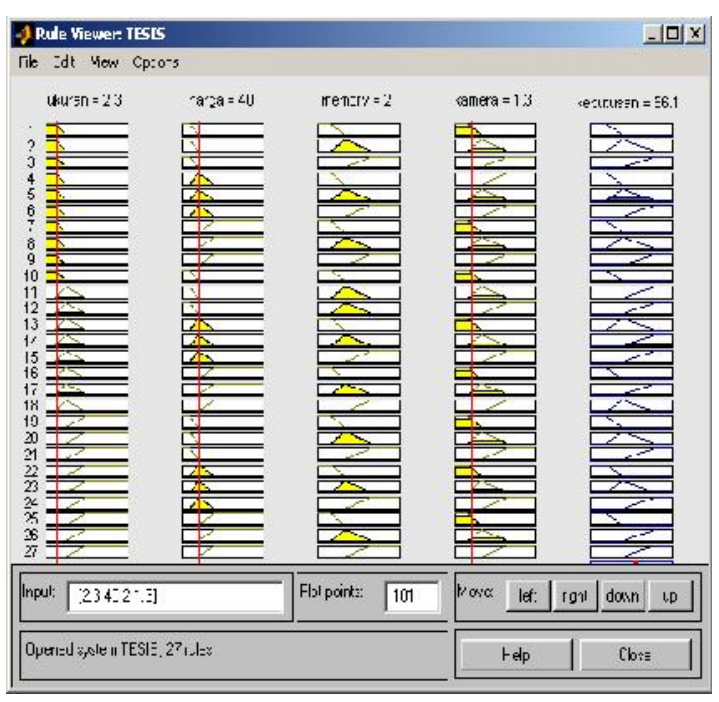

Gambar 6 Hasil Pengujian Menggunakan

Matlab

Pada gambar di atas hasil pengujian menggunakan matlab adalah 56,1 sedangkan perhitungan manual adalah 48 yang memiliki selisih sebesar 8,1 namun masih tetapdalam range yang sama dan meiliki keputusan yang sama juga yaitu Dipertimbangkan.

\section{KESIMPULAN}

Dari analisa di atas,maka dapat disimpulkan yaitu:

1. Sistem fuzzy dalam system ini dapat digunakan untuk pengambilan keputusan bagi pihak yang ada hubungannya dengan masalah pemilihan telepon selluler.

2. Pengujian terhadap hasil keputusan pemilihan telepon selluler menggunakan fuzzy Mamdani untuk konsumen dalam pemilihan telepon selluler berdasarkan kriteria yang diberikan.

3. Setelah menggunakan system ini dapat menentukan pemihan telepon selluler dengan hasil yang objektif berdasarkan kriteria yang ada.

\section{DAFTAR PUSTAKA}

RizkyPahlevi, Wahyu OktriWidyarto, Tb.AiMunandar. 2013. "Implementasi Fuzzy Mamdaniuntuk Penentuan Pengadaan Kartu Operator pada Distributor Kartu Perdana PT. XYZ” Prosiding Seminar Nasional Industrial Service (SNIS) III. Fakultas Teknik Universitas Serang Raya.

Ibrahim Rawadeh, Abbas Al-Refaie and Hamzeh Arabiyat. 20013. "Developing a Fuzzy Logic Decision System For Strategic Planning in Industrial Organizations" International Journal of Intelligent System and Application in Engineering. ISSN : 2147-6799.

Shofwatul 'Uyun. 2009.'Aplikasi Basisdata Fuzzy Berbasis Web untuk Pemilihan Handphone" ISSN : 0216 - 0644.Vol.5, No.1.

SherlyJ ayanti, Sri Hartati. 2012. "Sistem Pendukung Keputusan Seleksi Anggota Paduan Suara Dewasa Menggunakan Metode Fuzzy Mamdani”. Vol. 6, No.1, ISSN : $1978-1520$.

Heru DibyoLaksono, Hansi Effendi. 2011. "Aplikasi Logika Fuzzy pada Perkiraan Kebutuhan Energi Listrik Jangka Panjang di Provinsi Sumatera Barat sampaitahun 2008".Jurnal Teknologi Informasidan Pendidikan.Vol. 3 No.1.

Setionodan Sofa Marwoto. 2010. "Pemodelan Logika Fuzzy Terhadap Kerusakan Jembatan Beton". Media Teknik Sipil, Vol. X. ISSN : 1412-0976

Kusuma Sri, Purnomo Hari. 2013. "Buku Aplikasi Logika Fuzzy Untuk Pendukung Keputusan”. Yogyakarta. Pusat Penerbitan GrahaIlmu. Cet.ke.2 